\title{
Cenários de aprendizagem e noções de saúde: a percepção dos estudantes de Psicologia sobre sua formação
}

Scenarios of learning and understanding health: the perception of Psychology students on their formation

Escenarios de aprendizaje y nociones de salud: la percepción de los estudiantes de Psicología sobre su formación

\section{Daniele Rodrigues Souza Carmona* \\ Cássia Beatriz Batista ${ }^{* *}$}

\begin{abstract}
Resumo
O estudo, desenvolvido no curso de Psicologia de uma universidade privada de Belo Horizonte, visou a conhecer as concepções de saúde e a formação profissional construídas na trajetória acadêmica dos estudantes. De cunho exploratório, realizou-se aplicação de questionários e grupo focal nos discentes veteranos de Psicologia. Os estudantes tomam a definição de saúde da OMS como referência em seus discursos sobre a concepção de saúde; identificam um conjunto de cenários de aprendizagem em saúde presentes na formação, em que se destacam os estágios supervisionados e algumas disciplinas em detrimento de outros espaços menos vivenciados, como a pesquisa e a extensão; observam que as temáticas da saúde mais presentes na formação em Psicologia são "saúde mental" seguida de "saúde e trabalho". A trajetória dos estudantes pesquisados demonstra as dimensões formais presentes na graduação bem como os aspectos instituintes em andamento, especificamente no ensino-aprendizagem em saúde, incentivadas principalmente pelo programa Pró-Saúde.
\end{abstract}

Palavras-chave: Formação em saúde. Curso de Psicologia. Cenários de aprendizagem. Noções de saúde.

\begin{abstract}
The study, conducted in psychology course at a private university in Belo Horizonte, aimed to identify the concepts of health and training built into the academic career of the students. In exploratory way, the study
\end{abstract}

\footnotetext{
Texto recebido em dezembro de 2012 e aprovado para publicação em agosto de 2014.

Pós-graduanda no curso Gestão de Políticas Públicas em Gênero e Raça pela Universidade Federal de Viçosa (UFV), graduada em Psicologia pela Pontifícia Universidade Católica de Minas Gerais (PUC Minas), analista de Políticas Públicas na Prefeitura Municipal de Belo Horizonte. Endereço: CREAS - Centro de Referência Especializado de Assistência Social. Avenida Afonso Pena, 941, 1 andar - Centro, Belo Horizonte-MG, Brasil. CEP: 30130-003. E-mail: dani.87.carmona@gmail.com.

** Doutora, mestra e graduada em Psicologia pela Universidade Federal de Minas Gerais (UFMG), professora no Departamento de Psicologia da Universidade Federal de São João del-Rei (UFSJ), Campus Dom Bosco. Endereço: Dpsic - Departamento de Psicologia - Campus Dom Bosco - UFSJ. Praça Dom Helvécio, 74 - Bairro Fábricas, São João del-Rei - MG, Brasil. CEP 36301-160. E-mail: cassiabeatrizb@gmail.com.
} 
was conducted with questionnaires and focus group students in veterans' psychology course. Students take the WHO's definition of health as the reference in their speeches on the concept of health; identify a set of learning scenarios in health present in its shaping, in which we highlight the supervised internships and some disciplines over others less experienced such as research and extension; observe that the themes the most present in health psychology training are "mental health" followed by "health and work". The trajectory of the students surveyed demonstrates the dimensions present in the formal graduation, as well as instituting ongoing aspects, specifically in the teaching-learning processes, encouraged mainly by Prohealth program.

Keywords: Training in health. Psychology course. Learning scenarios. Understanding health.

\section{Resumen}

El estudio, , desarrollado en el curso de psicología en una universidad privada en Belo Horizonte, tuvo como objetivo identificar los conceptos de salud y la formación profesional construidos en la carrera académica de los estudiantes. Con carácter exploratorio, se realizó la aplicación de cuestionarios y de grupo focal a alumnos veteranos del curso de psicología. Los estudiantes toman la definición de salud de la OMS como una referencia en sus discursos sobre el concepto de salud, identifican un conjunto de escenarios de aprendizaje en la salud presentes en la formación, en el que se destacan las prácticas supervisadas y algunas disciplinas, en detrimento de otros espacios con menos vivenciados como la investigación y la extensión; se observa que las temáticas de salud más presentes en la formación en psicología son "salud mental" seguida de "salud y trabajo". La trayectoria de los estudiantes analizados demuestra las dimensiones formales presentes en la graduación, así como los aspectos instituyentes en marcha, específicamente en los procesos de enseñanza-aprendizaje en salud, incentivados principalmente por el programa Pro-Salud.

Palabras clave: Formación en salud. Curso de Psicología. Escenarios de aprendizaje. Nociones de salud.

\section{Introdução}

formação de profissionais para o trabalho em saúde é um aspecto histórico
que trazem seu arcabouço construções e mudanças de paradigmas conectados
com cada momento histórico, em âmbitos nacional e internacional. A formação em saúde é foco de atenção das gestões públicas no Brasil, ponto que se delineia como preocupação social antes mesmo da Constituição brasileira e que tem sido alvo de investimentos conforme é reconhecida como um dos pilares 
fundamentais na concretização dos objetivos do Sistema Único de Saúde (SUS), o que justifica inclusive a realização do estudo aqui apresentado.

Nesse contexto, o Programa de Reorientação da Formação de Profissionais de Saúde (Pró-Saúde) (Brasil, 2009) tem sido uma das açôes estratégicas dos ministérios da Saúde e da Educação, de incentivo a formação de trabalhadores mais próximos das demandas da população e do modelo de atenção brasileiro, destinando apoio técnico e financeiro aos cursos de saúde das instituiçôes de ensino superior (IES), entre os quais a graduação em Psicologia, eleita neste estudo como campo de investigação. A formação em Psicologia vem sofrendo diversas transformações nos últimos anos, entre as quais as modificações na educação dos profissionais, visando a prepará-los para atuar também nos serviços de atenção à saúde pública brasileira (Guareschi, Machry, Reis, Dhein \& Bennemann, 2012). Ressalta-se que, entre as mudanças já visíveis, observase "a aproximação da Psicologia às necessidades sociais, a inserção dessa área na proposta do Ministério da Saúde de formação de profissionais para o SUS, e a implantação das Diretrizes Curriculares Nacionais da psicologia, contemplando os objetivos do SUS" (Guareschi et al., 2012, p. 504).

Nesse sentido, o curso de Psicologia estudado passa a contar com um incentivo do Pró-Saúde para reorientar sua formação, fortalecendo a implantação das novas Diretrizes Curriculares Nacionais que, por sua vez, indicam aspectos centrais para formação de psicólogos, como a noção ampliada de saúde, a integralidade, a interdisciplinaridade e a articulação teoria-prática, entre outros.

Nosso estudo é resultado de uma investigação ${ }^{1}$ sobre a percepção dos alunos do curso de Psicologia de uma universidade privada em relação à formação em saúde vivenciada ao longo da graduação, tendo como pano de fundo a inserção do referido curso no Pró-Saúde desde 2008. Dessa forma, a escolha dos sujeitos de pesquisa do curso de Psicologia consistiu na aposta de que é essencial, em um processo de mudanças, conhecer a percepção dos alunos, alvo desse processo de reorientação da formação. Assim, a pesquisa teve como objetivo conhecer a percepção do corpo discente de um curso de Psicologia sobre a formação em saúde proporcionada pela graduação. Mais especificamente, buscou-se identificar as noções dos alunos sobre saúde e política de saúde pública e mapear os cenários de aprendizagem em saúde experimentados pelos estudantes durante a formação. Vale ressaltar que o curso de Psicologia não forma exclusivamente profissionais para a saúde, é uma formação híbrida entre Saúde, Ciências Humanas e Sociais, o que torna pertinente a discussão sobre quais cenários de aprendizagem em saúde são ofertados no curso. 


\section{Procedimentos metodológicos}

No desenvolvimento deste estudo, optou-se por uma perspectiva metodológica de cunho quanti-quali, partindo da ideia de complementaridade entre as duas abordagens na coleta e interpretação dos dados (Minayo, 2004; Minayo \& Sanches, 1993; Serapioni, 2000; Turato, 2005). A coleta dos dados se deu ao longo do ano de 2011 e, dentro dessa proposta, foram utilizadas então as técnicas de grupo focal (Kind, 2004) e de questionário, ambas com alunos do curso de Psicologia estudado.

A pesquisa optou por contemplar alunos dos $8^{\circ}, 9^{\circ}$ e $10^{\circ}$ períodos, ou seja, períodos finais do curso, visando a alcançar os graduandos que vivenciaram o processo de implantação do programa Pró-Saúde ao longo da formação e que, por estarem em fase de conclusão do curso, tinham mais condiçôes de avaliar o percurso formativo. $\mathrm{O}$ número total de alunos cursando esses últimos períodos, somando-se os dois turnos, perpassava cerca de 300 estudantes.

Tanto o roteiro de entrevista para o grupo focal quanto os questionários foram elaborados buscando compreender as vivências e aprendizados em saúde no curso com base nas trajetórias acadêmicas dos alunos, bem como suas percepções em relação a essas vivências e aprendizagens. $O$ temário para o grupo focal foi previamente elaborado, embora flexível o suficiente para permitir a fluidez e espontaneidade da conversa. Esse temário se constituiu por questóes abertas que buscavam investigar as concepçōes sobre saúde, política de saúde pública e Pró-Saúde; a percepção sobre a relação Psicologia e saúde; a identificação de temáticas e de cenários de aprendizagem em saúde presentes na formação; e a avaliação dos discentes em relação à formação em saúde proporcionada no curso.

Realizamos primeiramente o grupo focal, no qual elegemos uma amostra intencional de alunos com experiências e maior participação nos espaços de aprendizagem em saúde dentro do curso. Esses alunos foram identificados pela própria equipe de pesquisa e por indicação de professores da área da saúde. Foram convidados 11 alunos, dos $8^{\circ}, 9^{\circ}$ e $10^{\circ}$ períodos do curso de Psicologia, dos turnos da manhã e da noite, que assinaram o termo de consentimento livre e esclarecido conforme Resolução CNS 196/1996 e Comitê de Ética em Pesquisa da universidade estudada, que aprovou o Projeto de Pesquisa CAAE 0252.0.213.000-10.

Para a condução do grupo focal, além da moderadora, que tinha como função facilitar a conversa sobre a temática e manter o grupo em interação, duas auxiliares de pesquisa participaram dessa coleta de dados. $\mathrm{O}$ debate se estendeu bastante 
nos primeiros tópicos de discussão, e optamos por marcar mais um encontro com o mesmo grupo de alunos para vencermos todos os pontos do roteiro. Assim, o grupo se reuniu por duas vezes na própria universidade, totalizando quatro horas de gravação, que foram transcritas e depois analisadas.

A partir do grupo focal, o questionário foi elaborado e passou também por um pré-teste com seis alunos, que nos auxiliou na organização das questôes do roteiro, visando à elaboração de perguntas que fossem facilmente compreendidas pelos respondentes e uma organização sequencial das questóes e das opções de resposta. A aplicação do questionário foi realizada nas salas de aula, com permissão dos professores, nos turnos da manhã e da noite, atingindo um total de cem alunos respondentes voluntários.

Para o tratamento dos dados, nós nos orientamos pela perspectiva da análise do conteúdo proposta por Bardin (2004) e pela análise documental de Cellard (2008). As temáticas de análise eleitas foram também desenvolvidas à luz da literatura atual sobre Psicologia e saúde pública e formação superior em saúde (Carvalho e Ceccim, 2006; Ferreira Neto, 2004; Spink, 2003). As informaçôes obtidas nos questionários foram sistematizadas em planilha do Excel, possibilitando a representação de algumas categorias em gráficos, como veremos mais adiante.

Os participantes do grupo focal serão apresentados neste artigo por meio de nomes fictícios. No relatório da pesquisa, os dados do grupo focal foram organizados em quatro categorias que retratam as percepçóes dos alunos sobre conceitos construídos e práticas vivenciadas ao longo do percurso formativo:

a) percepção sobre o conceito de saúde;

b) currículo de Psicologia: temáticas e cenários de aprendizagem em saúde;

c) os diálogos entre formação e prática profissional em saúde; e

d) o percurso em saúde da formação de psicólogos. Optamos aqui por apresentar as duas primeiras categorias desse estudo.

A categoria "percepção sobre o conceito de saúde" buscou entender o modo como os alunos concebem a ideia de saúde e no que se baseiam para formular suas concepçôes. A categoria "currículo de Psicologia: temáticas e cenários de aprendizagem em saúde", por sua vez, evidenciou quais são as temáticas e os espaços de aprendizagem no curso que os alunos identificam como temas e cenários de aproximação e construção de saberes em saúde. A divisão em 
categorias foi apenas didática, visando a facilitar a compreensão, mas não almejou imprimir a ideia de que as concepções, críticas e posicionamentos dos alunos sobre saúde, Psicologia e formação tenham se dado de modo fragmentado. Inclusive, de forma geral, os alunos se referiram a essas dimensóes de modo muito relacionado, como veremos em alguns trechos de entrevistas.

De modo articulado, apresentaremos as análises geradas com base nos dados dos questionários; nas duas categorias de análise do grupo focal já anunciadas; e na análise documental (Cellard, 2008) do currículo pedagógico do curso, organizadas em dois grandes tópicos: a noção de saúde para o corpo discente e os cenários de aprendizagem em saúde.

\section{A noção de saúde para o corpo discente de Psicologia}

Nas concepções de saúde apresentadas pelos alunos, em 75\% dos questionários respondidos e também nos grupos focais, observamos uma noção generalizada e ampla de saúde conforme propõe a Organização Mundial de Saúde (OMS), revelando uma forte difusão desta na formação dos discentes. Esse dado não é surpreendente, tendo em vista que essa concepção é reforçada nos ideais do SUS e nas diretrizes curriculares e, portanto, nas políticas de promoção, prevenção e reabilitação da saúde.

Foram recorrentes definições de saúde como "bem-estar físico, mental e social"; dimensão "biopsicossocial"; "dependente de diversos fatores"; acesso aos direitos básicos, como moradia, alimentação, segurança, educação, lazer; e, portanto, como um processo que não se restringe à "ausência de doença”. Os discentes enfatizaram o aspecto positivo desse conceito, conforme permite uma ampliação da compreensão do que vem a ser saúde. "A saúde é um bem-estar físico, mental, social, religioso, político, econômico, tudo que traz bem-estar pro sujeito é uma, é uma dimensão de saúde, gera saúde pra ele ou gera doença” (Rosa - bolsista de iniciação científica).

Os participantes do grupo também apontam aspectos considerados negativos nessa perspectiva, como seu caráter utópico e normatizador.

Quando a gente vai pro conceito da Organização Mundial de Saúde, eu tenho a impressão de um conceito de saúde utópico e que tenta prescrever o que é saúde, como se a saúde fosse algo que pudesse ser mesmo, abranger tudo, toda a pessoa. [...] Esse conceito de saúde normatizado difere de pessoa pra pessoa, e que a gente, como profissional, tem que dar conta de... Ser maleável com esse conceito (Girassol - bolsista de extensão). 
Em algumas respostas, coexistem noções discrepantes de saúde que tanto afirmam uma definição ampliada quanto apresentam a saúde como uma condição de "não doença", de "ausência de distúrbios ou disfunções orgânicas e psíquicas" e de "ausência de sofrimento físico ou mental".

Além disso, em relação à definição de saúde como "completo estado de bemestar" colocado pela OMS, identifica-se também uma interpretação dos alunos pautada numa completude e plenitude a ser alcançada pelos sujeitos saudáveis. Essa ideia de condição de saúde dos sujeitos, por vezes, leva os estudantes a conceber o sujeito saudável como aquele que não apresenta qualquer problema físico ou psíquico, mostrando-se, assim, conflitante com a própria definição ampliada de saúde que afirmaram.

Esse paradoxo trazido pelos alunos, tanto nos questionários quanto no grupo focal, em relação à definição de saúde difundida pela OMS converge com a compreensão de Campos e Campos (2006). Para esses autores, se, por um lado, essa concepção contribuiu para a ampliação do modo de se pensar saúde, despertando diversos países para a necessidade de se construírem programas intersetoriais de promoção da saúde, por outro, a ideia de saúde como completo bem-estar lhe imprime um caráter estável e inatingível, dificultando uma orientação norteadora na criação e gestão de políticas de atenção e promoção à saúde.

Ainda pensando a concepção de saúde, os estudantes se posicionaram criticamente diante de abordagens que tratam a saúde com base no modelo biomédico, reduzindo os sujeitos aos manuais de diagnósticos, desafio a ser superado no dia a dia dos serviços de saúde mental, na opinião de Girassol:

Eu me deparei com isso, assim, essa normatização, e, mesmo dentro dos CAPS [Centro de Atenção Psicossocial], a gente é chamado muitas vezes dentro... no primeiro atendimento, a colocar uma hipótese diagnóstica, sendo que você nem conhece a história do sujeito. Então, tipo assim, ainda é uma saúde padronizada, normatizada, voltada ainda pra esses manuais [CID 10 e DSM], sabe, e isso é uma desconstrução diária e que não é fácil, porque a gente tem ainda, de certa forma, uma hierarquização desse saber (Girassol - bolsista de extensão).

Essa percepção de padronização e normatização dos sujeitos é problematizada nas discussões feitas pela Reforma Psiquiátrica, que luta pela substituição do modelo manicomial e pela mudança de paradigmas no tratamento e assistência às pessoas com sofrimento mental. As ações da Reforma se baseiam no ideal de uma sociedade sem manicômios, o que reflete não apenas a destruição dos 
muros físicos que aprisionavam e asilavam as pessoas com sofrimento mental nos hospitais psiquiátricos e o rompimento com o modelo biomédico de tratamento, mas um rompimento com as lógicas de normalização, exclusão, estigmatização e segregação das diferenças na sociedade (Birman, 1992; Amarante, 1996; Bezerra Júnior, 2007). Esse debate do campo da saúde mental, fortemente presente na formação em Psicologia, auxilia na compreensão das relaçôes entre saúde e sociedade e dos modos de existir e de produzir subjetividades.

No debate sobre o uso dos manuais diagnósticos como mais um dentre os instrumentos de diagnóstico que pode colaborar na construção do projeto terapêutico, Bezerra Júnior (2007) ressalta que o modo de conhecer e enxergar o sujeito não deve se reduzir a meras categorizações e classificações que acabam por criar identidades estereotipadas e estigmatizantes dos sujeitos loucos. E mais, salienta a relevância de se considerar a dimensão subjetiva das pessoas com sofrimento mental e, portanto, buscar conhecer a história de vida, o modo como se relacionam com os familiares; os vínculos e os desejos da pessoa também como recursos pertinentes ao diagnóstico e construção do projeto terapêutico. Nesse sentido, a participação e a autonomia dos sujeitos em seus processos de tratamento se tornam elementos considerados como promotores de saúde e cidadania.

Observamos, assim, que a percepção, os questionamentos e os apontamentos críticos apresentados pelos estudantes em relação à promoção da saúde no campo da saúde mental se mostraram afinados com as discussões veiculadas no movimento teórico e político da Reforma Psiquiátrica. Desse modo, os estudantes de Psicologia apresentaram uma visão problematizada da noção de saúde, estimulada pelas práticas de estágio e extensão em saúde mental, fortalecendo concepções de promoção da saúde pautadas nas práticas de coconstrução e participação dos usuários em seu processo de saúde e de construção das políticas públicas:

Saúde tá ligada a um sujeito em relação ao meio, ao contexto, a uma cultura... Esse trabalho de pensar o sujeito atrelado à saúde esbarra nesse conceito que é amplo e que esse sujeito, né, que também tem a sua complexidade (Maria - bolsista de iniciação científica)

Uma coisa que eu senti falta [no curso de Psicologia] é de uma prática voltada pra essa... pra construção de políticas de saúde visando... com participação do usuário. (Jasmim - bolsista de extensão). 
Todo esse ideário de promoção da saúde, de coparticipação dos usuários, de respeito à dignidade e a autonomia dos usuários, bem como às características socioterritoriais na criação e desenvolvimento de políticas e serviços é adotado pelo SUS, na forma de objetivos, princípios e diretrizes, conforme Vasconcelos e Pasche (2006). Todavia predominam em nossa sociedade práticas de promoção da saúde que não levam em consideração essa possibilidade de coconstrução entre usuários e profissionais das práticas de saúde e projetos terapêuticos. Nessa direção, os alunos do grupo focal identificam em suas experiências de estágio situações que, por vezes, exigem do psicólogo uma ação de adequação, padronização ou prescrição de estilos de vida saudáveis.

Todo dia, a gente é cobrado num sentido assim de padronizar a saúde, por exemplo, do paciente ou do morador, né, que seria o caso [Serviço Residencial Terapêutico] [...] Muitas vezes, a gente se depara com o técnico de Enfermagem que teve uma formação diferente da nossa, que, pra ele, fumar não é saúde, e ele quer muitas vezes que a gente venha com o nosso saber da Psicologia padronizar esse conceito de saúde (Girassol - bolsista de extensão).

Muitas áreas formam especialistas que vão entrar na área da saúde, mas, pra fazer o seu trabalho ali [de modo restrito] e não discutir saúde na sua complexidade [...] a falta de diálogos interdisciplinares... tem o conceito biomédico, né, a Psicologia tem um outro conceito de saúde. Então eu acho que cada área tem um conceito de saúde e não que ele individualmente esteja errado, mas eu acho que o que falta é justamente o diálogo interdisciplinar que a gente consiga, em vez de fragmentar o sujeito e de cada um pensar no seu conceito de saúde de uma maneira isolada, né, por que não tentar um diálogo e conseguir construir esse conceito? (João - bolsista de extensão).

Além da crítica as práticas de promoção da saúde pautadas em imperativos categóricos e vigilância dos hábitos de vida dos usuários, a fala da estudante reflete outra questão importante: o choque entre diferentes saberes e especificidades de cada profissão no campo da saúde, revelando mais uma vez a relevância da construção de práticas de diálogo e interdisciplinaridade, como bem pontua Spink (2003).

A crítica dos alunos em relação às lógicas padronizadoras que têm regido as ações de promoção da saúde é consonante com as discussóes retratadas por Carvalho (2004) e Stotz e Araújo (2004), autores que consideram que as propostas de promoção de saúde pautadas apenas no incentivo a mudanças de hábitos e estilos de vida são autoritárias, estigmatizantes, culpabilizadoras, convergentes com as ideias neoliberais e ainda pouco efetivas. 
Diante de todos esses desafios, os estudantes apostavam na disseminação e incorporação à prática de uma concepção ampliada de saúde como caminho necessário, tanto nos serviços quanto na formação superior, perspectiva que, na visão dos entrevistados, caracterizava-se como um dos objetivos do Pró-Saúde.

Fazer com que esse conceito de saúde esteja, atinja a todos os alunos, [...] a formação, a grade curricular, pra que se crie esse conceito amplo de saúde [...] e aí vê daqui alguns anos que está se formando profissional pensando igual a gente tá dizendo: "saúde, em qualquer lugar a que eu for, eu vou fazer”, seja em Psicologia, seja o profissional de Fisioterapia, de Enfermagem [...]. Então eu entendo o Pró-Saúde como isso, ampliar o conceito de saúde na formação, na grade, ampliar esse conceito... (Flor - bolsista de iniciação científica).

Nessa perspectiva, de uma formação que possibilite uma compreensão ampliada do que é saúde, a dimensão do controle social é avaliada pelos estudantes como um aspecto importante que também deve ser desenvolvido na graduação. Conforme o grupo, as possibilidades de o psicólogo trabalhar com o incentivo à participação social e política dos usuários da saúde são pouco abordadas ao longo do curso. Nesse sentido, os alunos ressaltaram que o SUS é fruto de uma história de lutas e movimentos da população e questionaram como tem se dado o posicionamento da população e dos profissionais da saúde diante do controle social, nos dias de hoje.

Em alguns momentos, o SUS não funciona [...] Às vezes, por má administração, mas aí vem de uma cultura nossa também de não fiscalizar, de não correr atrás, mas a maioria das pessoas usa o SUS e não sabe do Conselho de Saúde pra poder reivindicar isso, fiscalizar isso (Jasmin - bolsista de extensão).

Eu acho muito bonito, a teoria, o que tá previsto na legislação, na Lei 8.080, na Constituição Federal, na Lei 8.142, que fala justamente essa questão do controle social do SUS e das Conferências também, mas eu percebo que a prática requer um maior investimento da população (Sol - bolsista de iniciação científica).

Os apontamentos dessas alunas demonstram um cenário atual de esgotamento das iniciativas de participação democrática e política, aspecto assinalado por Campos e Campos (2006), que chegam a afirmar que a participação da população tem sido reduzida a uma participação representativa por meio do voto eleitoral. Todavia esses autores, assim como Stotz e Araújo (2004), reafirmam a importância de mobilização da população na construção e controle das políticas e enfatizam o potencial e lugar estratégico que os trabalhadores da saúde ocupam 
nesse sentido, podendo contribuir com o processo de informação, autonomia e empoderamento dos usuários. Ponto de vista que parece ser compartilhado pelos estudantes do curso de Psicologia.

Eu acho que as políticas ainda [são] muito feitas de cima pra baixo e... Dentro da academia, ainda se reproduz essa forma de se fazer política [...] O SUS, ele começou com uma demanda da população, começou com um movimento do usuário e hoje a gente vê pouco... É... e a academia incentiva pouco também que a gente faça um trabalho que motive os usuários (Jasmin, bolsista de extensão).

Como se pode notar, a compreensão de saúde apresentada pelos estudantes se constitui por um emaranhado de percepções. O modo como a própria noção de saúde é elaborada no campo teórico e legal, como são construídas as estratégias de promoção a saúde, como se estabelece os diagnósticos e os projetos terapêuticos, como ocorre a relação entre profissionais da saúde e usuários e as relações interprofissionais e a própria noção de sujeito são algumas das dimensões e tensôes que estão no cerne da concepção de saúde apresentada pelos estudantes, afinal, compreender a relação sujeito, saúde e sociedade em sua processualidade e dinamismo requer reconstruçôes conceituais e práticas constantes.

\section{Os cenários de aprendizagem em saúde}

Tomamos aqui a expressão cenários de aprendizagem como os espaços de formação presentes na graduação. Assim, disciplinas, estágios supervisionados, monografia, pesquisa ou iniciação científica, extensão, palestras e seminários são alguns dos cenários que constituem a formação acadêmica, tal como se verificou em estudos anteriores (Batista, Carmona, Matos \& Fonseca, 2010; Batista, Carmona \& Fonseca, 2014).

As fontes que subsidiaram as análises em relação aos cenários de aprendizagem em saúde no curso de Psicologia foram os dados dos questionários, as discussóes do grupo focal e a consulta aos currículos pedagógicos do curso do ano de 2000, 2003 e sua última atualização, em 2009.

Com base na questão número 7 do questionário, que investigava a opinião dos respondentes quanto à intensidade com que a temática "saúde" é abordada em cada cenário de aprendizagem da formação, deu-se a construção do gráfico 1: 
Gráfico 1. Cenários de aprendizagem em saúde ofertados na graduação

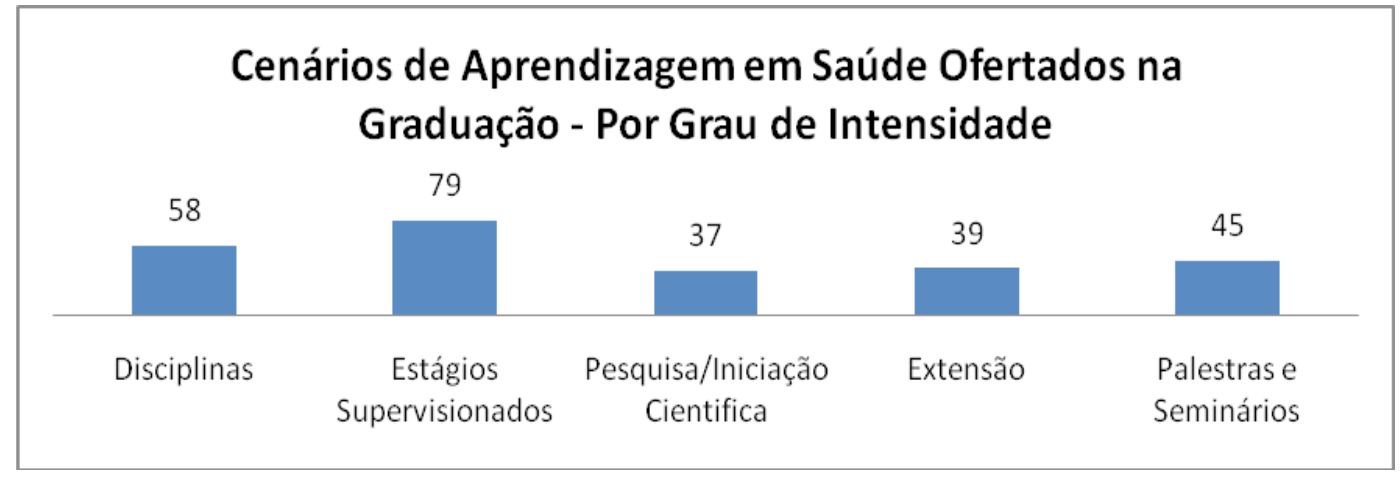

Fonte: Elaborado pelas autoras.

A primazia dos estágios supervisionados sobre os outros espaços de aprendizagem é um dado que se confirma mais uma vez, considerando pesquisa anterior sobre os cenários de ensino-aprendizagem em saúde no curso de Psicologia da mesma universidade (Batista et al., 2014).

Como se pode notar no gráfico, os estágios supervisionados, em primeiro lugar, e as disciplinas em sala de aula, em segundo, são, na visão dos estudantes, os espaços em que o contato com as discussões e práticas em saúde mais acontecem, em detrimento dos espaços de pesquisa, extensão e palestras/seminários, que são reconhecidos pelos estudantes como espaços ofertados com menor frequência e intensidade no curso. Nessa direção, em torno de 15\% dos estudantes respondentes informaram que desconheciam ofertas de aprendizagem em saúde nos cenários de pesquisa, extensão e palestras. Possivelmente essa diferença se deu pelo fato de as disciplinas e os estágios supervisionados serem atividades obrigatórias e regulares de ensino, previstas e regulamentadas pelo projeto pedagógico e oferecidas para todos os alunos, diferente das demais.

Os participantes do grupo focal, embora reconhecessem todos os cenários de aprendizagem presentes na graduação, também destacaram os estágios supervisionados como espaço em que a aproximação com a prática e as discussões em saúde era mais presente. Os estudantes descreveram experiências de estágios curriculares e extracurriculares em unidades básicas de saúde, hospitais, serviços substitutivos de saúde mental, como centros de atenção psicossocial, organizações não governamentais e residências terapêuticas, e serviços de tratamento e acompanhamento ao toxicômano, como comunidades terapêuticas e outros centros de recuperação de dependentes químicos.

Essas vivências de estágios em ambientes institucionais de trabalho possibilitam aos estudantes ampliar as práticas clínicas para além do espaço acadêmico da 
clínica-escola, localizada dentro da universidade, experimentando assim práticas clínicas mais contextualizadas e diversas, como pontuam Pereira e Ferreira Neto (2011), a partir de estudo exploratório sobre a graduação em Psicologia na mesma universidade pesquisada.

Coerente com a ideia de uma compreensão ampliada de saúde, os alunos apontaram também como experiências práticas em saúde os estágios em escolas por meio do Programa de Saúde na Escola (PSE) e do Programa de Educação Afetivo-Sexual (PEAS) do Estado de Minas Gerais; atuação com adolescentes, idosos e cuidadores informais de acamados, por meio do projeto Cuidando de Quem Cuida; e estágios voltados para mobilização social e redes sociais.

No grupo focal, a fala de uma estudante denota a importância dada pelos alunos às experiências de estágio em sua formação em saúde.

Aí a grande experiência pra mim, que mudou minha vida, acho que inclusive foi o que me abriu a porta pra estar hoje dentro da saúde mental [A estudante atua como estagiária de Psicologia na rede de residências terapêuticas de Santa Luzia] foi o estágio de autonomia na promoção de saúde. A gente fez um projeto, fomos a campo na UBS entrevistar profissionais, montamos um artigo de autonomia na promoção de saúde (Girassol - bolsista de extensão).

A estudante se referia aos estágios supervisionados obrigatórios de Prática Investigativa, realizados nos períodos iniciais do curso, a partir do segundo período, em que os graduandos escolhem um tema, de acordo com seus interesses e curiosidades, elaboram um projeto de pesquisa e, posteriormente, executamno, possibilitando uma aproximação inicial com a dimensão da pesquisa, como também apontam Pereira e Ferreira Neto (2011). Importantes para a formação, os estágios e a supervisão em pequenos grupos foram apontados pelos estudantes como um espaço que ampliava o conhecimento, no qual eram discutidas questóes que nem sempre eram abordadas em sala de aula, como se pode perceber na seguinte afirmação: "As experiências, é... no centro de saúde, que faz com que a gente entre em contato, leia textos, conhecemos a respeito do matriciamento, são questôes que a gente não é... estudou nas disciplinas em sala de aula" (Mel estagiária atenção primária).

Essa importância da aproximação do aluno com os serviços de saúde é pontuada por Campos et al. (2001), que defendem a inserção precoce dos alunos nas comunidades e o contato com a população e os espaços de trabalho em saúde. Essa interação entre escola e serviço, conforme os autores, contribui para que as instituições de ensino superior se aproximem das necessidades de 
saúde da população e das propostas do SUS, e, assim, assumam uma formação mais integrada aos serviços de saúde. Nesse sentido, os estágios supervisionados têm sido espaços privilegiados para que essa articulação escola-serviço aconteça, buscando modificar a prática e a formação dos profissionais da saúde.

Além da importância dada aos estágios supervisionados, os estudantes também destacaram as experiências vivenciadas nos projetos de extensão. $\mathrm{Na}$ visão dos estudantes, o envolvimento com a pesquisa e extensão convidava-os à responsabilidade de construção do conhecimento e de compartilhamento das experiências em eventos e produções científicas, evidenciando as possibilidades de articulação entre os cenários de aprendizagem.

A possibilidade de apresentar no Seminário de Extensão da Proex, de apresentar aqui nas SCAP [Semana de Ciência, Arte e Política, promovida anualmente pela universidade] e de ser muitas vezes convidada a fazer resumos, a fazermos artigos... O tanto que a gente tem que ler pra isso... (Girassol - bolsista de extensão).

Todavia, ainda há pouca participação dos estudantes nos espaços de pesquisa e extensão, levando em conta o universo total de estudantes matriculados. Esse dado se confirma, principalmente, por meio dos questionários, em que a captura dos respondentes se deu de modo aleatório; mas também na opinião dos participantes do grupo focal, que se reconheceram entre os poucos estudantes ou únicos de sua turma que se envolviam com a pesquisa ou extensão. Esse panorama não se dá apenas no campo da saúde, mas de modo geral, uma vez que a pesquisa e a extensão não são atividades curriculares obrigatórias, mas complementares, ainda que essa indissociabilidade esteja prevista no tripé da formação universitária.

De certa forma, essa situação de experiências restritas em projetos de pesquisa e de extensão, demonstra que, geralmente, um grupo fixo de alunos tende a participar mais das atividades extrassala (pesquisa, extensão e eventos científicos). Esses alunos, circulando em outros espaços institucionais, destacam-se e ampliam seus vínculos no ambiente universitário, como é o caso dos estudantes convidados a participar do grupo focal. Entrevistá-los permite alcançar um pouco da dimensão do currículo oculto ou paralelo, que, conforme Silva (2003) e Maia (2004), escapa ao currículo formal e se constitui nas relações e vínculos institucionais construídos entre os atores.

Nessa direção, os participantes do grupo focal que, devemos lembrar, foram escolhidos intencionalmente por sua participação e envolvimento maior com 
diferentes cenários de aprendizagem em saúde no curso, identificaram que há diversas possibilidades de construção de um aprendizado sobre saúde na formação em Psicologia e que, muitas vezes, passar por essa experiência dependeria do interesse e escolhas do próprio estudante, o que, mais uma vez, remete-nos à dimensão oculta do currículo no curso estudado.

Outro ponto retratado na pesquisa foi a percepção dos estudantes em relação à diversidade de áreas de atuação em saúde abordadas no curso. Pela análise da questão 4 do questionário, observou-se que "Saúde Mental" e "Saúde e Trabalho" são as categorias que os alunos identificam como mais abordadas ao longo da graduação, com destaque ainda maior da primeira. Esse dado também reitera os resultados da pesquisa documental realizada pelas autoras em 2009, na qual as mesmas temáticas foram identificadas entre as mais frequentes na formação em Psicologia (Batista et al., 2014). Já as áreas atenção primária a saúde, abuso de drogas e dependência química, atuação hospitalar, saúde da criança, do adolescente e do idoso são temáticas pouco ou razoavelmente abordadas na formação, conforme demonstra o gráfico 2 .

Gráfico 2. Áreas de atuação em saúde abordadas na graduação

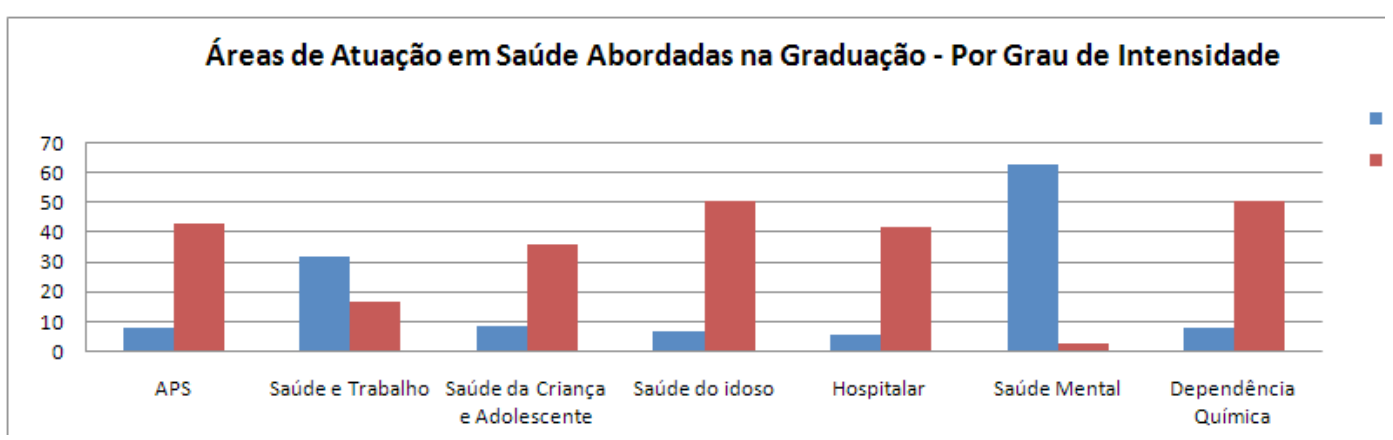

Fonte: elaborado pelas autoras.

Essa percepção dos alunos em relação à predominância da saúde mental na formação também aparece nas discussóes do grupo focal, incitando-nos a pensar esse cenário como efeito dos diversos acontecimentos históricos e sociais da reforma psiquiátrica, relacionados à inserção da Psicologia no campo da saúde pública via saúde mental, como bem analisa Ferreira Neto (2004). Essa perspectiva histórica também é explorada por Guareschi et al. (2012), ao retratar o processo de desospitalização e expansão dos serviços de saúde mental à rede básica de saúde como fatores impulsionadores da inserção dos psicólogos no campo da saúde pública, a partir da década de 1970. 
O grupo focal também abrangeu a visão dos participantes sobre a organização curricular do curso. Os discentes reclamaram a falta de maior contato ou contato tardio, durante a graduação, com conceitos e conhecimentos que, por vezes, eram-lhes exigidos ou necessários nos serviços dos quais eles chegavam para estagiar ou trabalhar. Análise essa coincidente com o desabafo feito pela autora Alessandra Barbosa Pereira, ex-aluna do curso de Psicologia estudado, quando diz: "O primeiro estágio ocorreu sem contextualização e discussões necessárias para a entrada em campo, o que gerou em mim grande ansiedade, sentimento de despreparo teórico e prático para lidar com situações complexas e com a dinâmica institucional" (Pereira \& Ferreira Neto, 2011, p. 248).

Nessa direção, deram-se as queixas dos alunos participantes do grupo focal, conforme trecho a seguir:

A gente entra na UBS, na saúde mental, e te cobram isso. Ah... o que que é o Pró-Saúde, o que que é o Humaniza SUS, o que que é isso, o que é aquilo... os parâmetros do SUS? Se não fosse esse estágio [se referindo ao estágio que fez em um Centro de Saúde], provavelmente com as matérias eu não teria acesso (Girassol - bolsista de extensão).

De modo geral, os estudantes entrevistados no grupo focal concordam que as disciplinas que compreendem a atuação em saúde deveriam ser lecionadas antes dos estágios profissionalizantes. Aqui os entrevistados estão se referindo às disciplinas "teorias e práticas em saúde mental" e "Psicologia e instituições de saúde", até então lecionadas no décimo período e de caráter optativo, relacionada à escolha das ênfases, como também criticam Pereira e Ferreira Neto (2011). Contudo, no currículo novo, em vigor desde 2010, isso já foi observado e modificado, como observaram os próprios estudantes.

A prática aqui [na universidade] auxilia muito, contudo, em relação à teoria mesmo, eu sempre vivia pensando porque que essa matéria de saúde que envolve o conceito de saúde pública, né [Psicologia e instituições de saúde], por que ela é só no nono, por que que ela não poderia ser antes. Mas houve uma modificação, né, [...] parece que, no novo currículo, os meninos estão vendo essa matéria mais recente, né. E eu vejo que isso é um avanço mesmo com relação a isso (Margarida - bolsista de extensão)

Como já pontuamos, as alterações no projeto político pedagógico do curso de Psicologia em 2009 trouxe reestruturações de disciplinas, ementas e períodos vislumbrando a formação em saúde dos futuros psicólogos em acordo com as 
DCN. O remanejamento das disciplinas possibilitou a antecipação da disciplina "Psicologia e instituições de saúde", que deixou de ser oferecida no último período e passou a ser lecionada no sexto período com o nome "Psicologia e saúde", ampliando também o escopo e debate em saúde. Nesse mesmo período, também foi implementada uma nova disciplina denominada "Saúde coletiva e saúde mental". Essas modificações curriculares bem como a redefinição das ênfases do curso foram fortalecidas pelo Pró-Saúde. As ênfases foram definidas como gestão, processos de subjetivação e instituiçôes e o cuidado, processos psicossociais e saúde, ambas atravessadas pela política de saúde. Além disso, previram-se disciplinas de integração de conteúdos e práticas, turmas menores e flexibilidade curricular para cursar as duas ênfases em anos diferentes.

Todavia o currículo dos estudantes que participaram dessa pesquisa era o antigo, uma vez que já haviam passado da metade da graduação quando da implantação do novo currículo. Então suas impressões eram de outro percurso formativo. Por outro lado, é importante assinalar que, embora não tenham sido submetidos à nova grade curricular, os discentes pesquisados sentiam efeitos dessas transformações por meio dos eventos científicos realizados, da possibilidade de acesso ao Laboratório de Saúde Coletiva, recém-implantado nesse período, bem como às pesquisas e práticas de extensão em saúde, e até mesmo pela mudança de posturas dos docentes e do clima institucional. Afinal de contas, já apontamos que o currículo também se constitui por dimensões ocultas e paralelas, além do prescrito (Maia, 2004).

Com relação à monografia, 8 dos 12 alunos que participaram do grupo expressaram que consideravam seu tema de pesquisa relacionado à dimensão da saúde, e muitos revelaram que o interesse de pesquisa desenvolvido na monografia tivera origem em estágios supervisionados, práticas de extensão ou eram continuidade de alguma pesquisa da qual participaram. Esse dado mostra que, em alguma medida, o objetivo de integração curricular, ou seja, de articulação entre ensino, estágios, pesquisa e extensão, é alcançado, como defende o Projeto Político-Pedagógico de 2009.

De modo geral, o grupo também se referiu aos primeiros estágios (momento que se caracteriza pelas visitas aos campos de atuação do psicólogo que são escolhidas pelos próprios alunos) como primeira oportunidade de aproximação com os campos da saúde. Todavia, a maioria dos alunos comenta que esse primeiro contato com o campo da saúde se restringe ainda a área hospitalar ou da Psicologia hospitalar, como denota a fala da aluna: 
No segundo período, nas práticas de visita a campo, uma das escolhas do grupo que eu participava foi visitar a Psicologia hospitalar e nós fomos ao hospital [...], um hospital público... na Santa Casa, depois também a gente foi no Mater Dei, que não é público" (Sol - bolsista de iniciação científica).

Esse fato nos permite pensar que os estudantes iniciantes no curso de Psicologia tendem a trazer consigo uma representação do psicólogo colada no imaginário social de um profissional voltado para a dimensão da doença e da cura, o que justifica o interesse de muitos estudantes pelo hospital como campo de atuação. Contudo não podemos esquecer que essa percepção está ligada a um contexto histórico, uma vez que a área hospitalar e da saúde mental são espaços institucionais de assistência à saúde nos quais a Psicologia está inserida há mais tempo, sendo, portanto, campos tradicionais da atuação psi em âmbito internacional e nacional, de acordo com o resgate histórico feito por Herter, Boschi, Silva Neto e Araújo (2006).

Outro ponto em destaque sobre os cenários de aprendizagem é o conjunto de disciplinas biológicas e as explicitamente declaradas como da saúde que foram citadas pelos estudantes, tanto nos questionários quanto no grupo focal. Assim, "neuroanatomia", "neurobiologia", "fisiologia", "psicopatologia", "Psicologia e instituiçõos de saúde", "teorias e práticas em saúde mental", "saúde mental e trabalho" foram as disciplinas mais lembradas e apontadas pelos participantes da pesquisa. Esse dado denota resquícios do paradigma biológico na concepção de saúde apresentada pelos discentes, evidenciando, mais uma vez, um discurso paradoxal. Ou seja, embora as concepçôes, as críticas e os posicionamentos dos alunos estivessem impregnados do discurso idealizado e veiculado pelo SUS e pelo Pró-Saúde, há momentos em que evidenciam uma visão de saúde ainda colada no paradigma biomédico.

A coordenação do curso de Psicologia e o corpo docente têm reunido esforços para mudar essa realidade, o que se expressa de modo mais evidente desde a implantação do último projeto político-pedagógico de acordo com estudos anteriores das pesquisadoras (Batista et al., 2010). Ações como o Pesquisa ao Alcance de Todos (PAT), em que são realizadas oficinas de elaboração de projetos de pesquisa, incentivando e monitorando os alunos na inscrição ao Programa Institucional de Bolsas de Iniciação Científica (Probic), incentivos dos professores à pesquisa e atividades extensionistas e ações de ampla divulgação dos processos de seleção de bolsistas para os projetos de pesquisa e extensão dentro da unidade têm se tornado cada vez mais frequentes no contexto do curso pesquisado, ainda que os recursos para tais açôes sejam escassos (Batista et al., 2014). 


\section{Considerações}

A pesquisa realizada evidenciou uma forte difusão da concepção de saúde da OMS, no contexto teórico e prático da saúde, o que contribui tanto para ampliação da noção de saúde quanto para sua restrição e normatização a certo "estado de bem-estar", deflagrando, portanto, interpretações conflitantes, como sinalizam os estudantes pesquisados.

Por outro lado, vale uma análise mais ousada em relação aos aspectos conflitantes nas percepçóes, concepções e posicionamento dos estudantes no que diz respeito ao campo teórico e prático da saúde pública. Vivenciamos um momento em que a formação e as práticas de saúde ainda coladas na velha concepção de saúde, no modelo biologicista, biomédico e fragmentado do processo saúde-doença estão sendo repensadas, questionadas e problematizadas. E, nessa direção, abrem-se caminhos para novas possibilidades e paradigmas na forma de pensar e fazer saúde pública, tendo como princípios e diretrizes as ideias de integralidade, interdisciplinaridade, complexidade, entre outras. Assim, perguntamo-nos se as perspectivas paradoxais, apresentadas pelos estudantes e apontadas em vários momentos nesse artigo, dizem do próprio processo de transformação da formação, em que há o encontro do velho e do novo, do instituído e do instituinte.

Nesse sentido, esse movimento de transformação e de afirmação de novos paradigmas, em curso há muito tempo, tem, em alguma medida, alçando os estudantes pesquisados. Pois, de modo geral, em sua tentativa de construção de uma concepção de saúde, os estudantes demonstram o aspecto complexo desse processo, já que é sempre uma compreensão que tem como efeito não apenas uma concepção de saúde, mas várias, e que atravessam o dia a dia da prática profissional nos serviços de saúde e os cenários de ensino-aprendizagem presentes na formação superior.

Noquediz respeitoaoscenáriosdeaprendizagem emsaúdeidentificadosnocurso pesquisado, observou-se que é ampla a oferta tanto de espaços de aprendizagem quanto de temáticas em saúde, embora as vivências e experimentações da maioria dos estudantes se concentrem nos espaços tradicionais e formais, como as salas de aula e os estágios obrigatórios, e na temática da saúde mental, não obstante processos de mudanças ter sido alavancados, principalmente em relação à menor participação de alunos na pesquisa e extensão.

Percebem-se o trabalho e o investimento da coordenação e corpo docente do curso na tentativa de instituir e fortalecer ideias e práticas de aprendizagem voltadas para a saúde pública dentro do curso de Psicologia estudado. Essa postura impulsionada, entre outras coisas, pelos incentivos do programa Pró- 
Saúde ao curso desde 2009 possibilitou mudanças curriculares; criação de novos espaços e cenários de aprendizagem em saúde, como o laboratório de saúde coletiva e a realização de eventos científicos locais focados no tema, em que se buscava a interlocução com os serviços parceiros em que ocorriam os estágios curriculares; despertou a sensibilização e interesse de docentes e discentes para o campo da saúde, fomentando, assim, o desenvolvimento tanto formal quanto informal de grupos de estudo e pesquisa em saúde. Todavia vale dizer que o curso de Psicologia pesquisado assim como vários outros cursos voltados para a saúde e, por que não dizer, os serviços de saúde, apenas iniciaram o movimento de mudanças necessárias para consolidação de uma cultura de formação realmente comprometida com as necessidades e princípios do sistema de saúde brasileiro. $\mathrm{E}$, nesse contexto, a interação escola-serviço permanece como um grande desafio na reorientação da formação de profissionais de saúde.

Por fim, não poderíamos deixar de dizer sobre os efeitos da pesquisa realizada nos sujeitos investigados e na própria equipe de pesquisa, evidenciando assim nossa concepção de pesquisa como um processo dialógico. Os métodos de pesquisa proporcionaram aos alunos uma aproximação das discussões e problematizaçóes em torno da saúde e da formação de profissionais para essa área, sendo chamados a coparticipar dos processos de reflexão e avaliação da formação em saúde oferecida em seu curso. Dessa forma, a pesquisa desencadeou nos alunos uma participação mais ativa e compartilhada diante do processo de formação, de modos de pensar e fazer saúde, tal como proposto pelo SUS. E, nesse sentido, consideramos que o processo de pesquisa também é uma forma de intervenção na realidade. 


\section{Referências}

Amarante, D. P. (1996). O homem e a serpente: outras histórias para loucura e a psiquiatria. Rio de Janeiro: Fiocruz.

Bardin, L. (2004). Análise de conteúdo. (3a ed.). Lisboa: Ed. 70.

Batista, C. B., Carmona, D. S. \& Fonseca, S. L. (2014). A formação em saúde e os cenários de aprendizagem no curso de Psicologia. Revista Argumento, 32, $17-25$.

Batista, C. B., Carmona, D. S., Matos, D. N. \& Fonseca, S. L. (2010). Psicologia e saúde pública: reorientando a formação de profissionais da saúde no Brasil. In Anais, 5 Colóquio Luso-Brasileiro, 9 Colóquio sobre questôes curriculares: debater o currículo e seus campos: politicas, fundamentos e práticas. (pp. 5298-5309). Portugal: Porto.

Bezerra Junior, B. (2007). Um apelo à clínica: nem o respaldo da norma, nem o extravio na dor. In A. M. Lobosque(Org.), A Reforma Psiquiátrica quequeremos, por uma clínica antimanicomial. Encontro Nacional de Saúde Mental, Caderno Saúde Mental (pp. 23-31). Belo Horizonte: ESP-MG. Recuperado a partir de http:/www.esp.mg.gov.br/wp-content/uploads/2009/06/caderno-saudemental.pdf

Birman, J. A. (1992). Cidadania tresloucada. In B. Bezerra Jr. \& P. D. Amarante (orgs). Psiquiatria sem hospicio: contribuição ao estudo da reforma psiquiátrica. (pp. 71-90). Rio de Janeiro: Relume-Dumará.

Brasil. Ministério da Saúde. Ministério da Educação. (2009). Programa Nacional da Formação Profissional em Saúde: Pró-Saúde: objetivos, implementação e desenvolvimento potencial. Brasília: Ministério da Saúde. Recuperado a partir de http://www1.pucminas.br/documentos/edital_prosaude.pdf

Campos, F. E., Ferreira, J. R., Feuerwerker, L., Sena, R. R., Campos, J. J. B., Cordeiro, H., Cordoni Junior, L. (2001). Caminhos para aproximar a formação de profissionais de saúde das necessidades da atenção básica. Revista Brasileira de Educação Médica, 25(2), 53-59. Recuperado a partir de http://www.pucsp. $\mathrm{br} /$ prosaude/downloads/bibliografia/caminhos_aproximar.pdf

Campos, R. T. O. \& Campos, G. W. S. (2006). Coconstrução de autonomia: o sujeito em questão. In G. W. S. Campos, M. C. S. Minayo, M. Akerman, M. Drumond Jr. \& Y. M. Carvalho (Orgs.), Tratado de saúde coletiva. (pp. 669688). São Paulo: Hucitec, Rio de Janeiro: Fiocruz. 
Carvalho, S. R. (2004). As contradições da promoção a saúde em relação a produção de sujeitos e mudança social. Ciência e Saúde Coletiva, 9(3), 669678. Recuperado a partir de http://www.scielo.br/pdf/csc/v9n3/a13v09n3.pdf

Carvalho, Y. M. \& Ceccim, R. B. (2006). Formação e educação em saúde: aprendizados com a saúde coletiva. In G. W. Campos et al. (Org.), Tratado de Saúde Coletiva (2a ed.). (pp. 137-170). São Paulo: Hucitec, Rio de Janeiro: Fiocruz.

Cellard, A. (2008). Análise documental. In J. Poupart et al. A pesquisa qualitativa: enfoques epistemológicos e metodológicos. A. C. Nasser (Trad.). Petrópolis: Vozes.

Ferreira Neto, J. L. (2004). A formação do psicólogo: clínica, social e mercado. São Paulo: Escuta, Belo Horizonte: Fumec/FCH.

Guareschi, N. M. F., Machry, D. S., Reis, C., Dhein, G. \& Bennemann, T. (2012). Implicações da área das biomédicas na formação do psicólogo para o SUS. Psicologia Argumento, 30(70), 503-513.

Herter, M. L., Boschi, M. F. L., Silva Neto, N. A. \& Araújo, T. C. C. F. (2006). Psicologia. In A. E. Haddad et al. (Orgs.), A trajetória dos cursos de graduação na área da saúde: 1991-2004. (pp. 412-453). Brasília: Instituto Nacional de Estudos e Pesquisas Educacionais Anísio Teixeira.

Kind, L. (2004). Notas para o trabalho com a técnica de grupos focais. Psicologia em Revista, 10(15), 124-136.

Maia, J. A. (2004). O currículo no ensino superior em saúde. In N. A. Batista \& S. H. Batista (Orgs.), Docência em saúde: temas e experiências. (pp. 101-133). São Paulo: Senac.

Minayo, M. C. S. (2004). O desafio do conhecimento: pesquisa qualitativa em saúde. São Paulo: Hucitec.

Minayo, M. C. S. \& Sanches, O. (1993). Quantitativo-qualitativo: oposição ou complementaridade? Cadernos de Saúde Pública, 9(3), 239-262. Recuperado a partir de http://www.scielo.br/pdf/csp/v9n3/02.pdf

Pereira, A. B. \& Ferreira Neto, J. L. (2011). Problematizações sobre a formação em psicologia e o campo da saúde. In L. Kind, C. B. Batista \& L. Gonçalves (Orgs.), Universidade e serviços de saúde: interfaces, desafios e possibilidades na formação profissional em saúde. (pp. 244-262). Belo Horizonte: Editora PUC Minas. 
Serapioni, M. (2000). Métodos qualitativos e quantitativos na pesquisa social em saúde: algumas estratégias pra a integração. Revista Ciência e Saúde Coletiva, 5(1), 187-192. Recuperado a partir de http://www.scielo.br/pdf/csc/ v5n1/7089.pdf

Silva, T. T. (2003). Documentos de identidade: uma introdução às teorias do currículo. (2a ed., 5a reimpressão). Belo Horizonte: Autêntica.

Spink, M. J. P. (2003). Psicologia social e saúde: práticas, saberes e sentidos. Petrópolis: Vozes.

Stotz, E. M. \& Araújo, J. W. G. (2004). Promoção da saúde e cultura política: a reconstrução do consenso. Saúde e Sociedade, 13(2), 5-19. Recuperado a partir de http://www.scielo.br/pdf/sausoc/v13n2/02.pdf.

Turato, E. R. (2005). Métodos qualitativos e quantitativos na área da saúde: definiçōes, diferenças e seus objetos de pesquisa. Revista de Saúde Pública, 39 (3), 507-514. Recuperado a partir de http://www.scielo.br/pdf/rsp/v39n3/24808. pdf

Vasconcelos, C. M. \& Pasche, D. F. (2006). O Sistema Único de Saúde. In G. W. S. Campos, M. C. S. Minayo, M. Akerman, M. Drumond Júnior, Y. M. Carvalho. (Orgs.), Tratado de saúde coletiva. (pp. 531-562). São Paulo: Hucitec, Rio de Janeiro: Fiocruz. 